\title{
A model to evaluate the effectiveness of environmental projects
}

\author{
E. Laniado ${ }^{1}$, S. Vaghi ${ }^{2}$, E. Amodeo ${ }^{2}$, A. Capriolo ${ }^{3} \&$ R. Mascolo ${ }^{3}$ \\ ${ }^{1}$ CNR - IEIIT e Poliedra - Politecnico di Milano, Italy \\ ${ }^{2}$ Poliedra - Politecnico di Milano, Italy \\ ${ }^{3}$ ISPRA (Istituto Superiore per la Protezione e la Ricerca Ambientale), \\ Italy
}

\section{Abstract}

The paper presents a methodological model to evaluate and compare the results of environmental projects implemented by local administrations with public funds.

This model is an implementation of the "model for the ex-post evaluation of environmental projects”, developed by ISPRA (Italian National Institute for Environmental Protection and Research). It takes into account the results of the test phase involving broad kinds of projects in various environmental sectors.

Even if the model was initially designed to report benefit obtained by already implemented projects, it can also be used to guide public administrations funding towards the most relevant environmental priorities in a given area, or towards the most effective option among different projects.

To this aim, the model gives a framework for the assessment of projects based on a common set of environmental sustainability objectives. It also identifies the "typical" environmental effects deriving from each kind of projects and defines a set of indicators and indexes useful to evaluate them.

The evaluation considers an overall balance of project environmental effects (direct and indirect, positive and negative), identifying four evaluation dimensions: effectiveness, impacts (impact is defined as "additional effect" of the project that is not consequent to its direct objectives), cost-effectiveness and efficiency evaluations.

The model and its tools (matrices, cause-effect chains, indicators and indexes) are described, giving examples from analysed case studies in the sectors of energy, sustainable mobility, water and waste treatment. 
In conclusion, the paper discusses how the model can be used in the decision making process in order to improve environmental policies effectiveness.

Keywords: environmental projects, project effectiveness, resource efficiency, assessment indicators.

\section{Introduction}

In this paper, we present a methodological model to evaluate and compare the results achieved by environmental projects developed by local administrations by means of public funding (using regional, national or EU economic resources), with the objective to optimize their use.

It synthesizes the outcomes of the research "Systems for assessing environmental projects effectiveness at local level”, conducted by Poliedra Politecnico di Milano, financed by ISPRA - the Institute for Environmental Protection and Research. It proposes an evaluation model directly deriving and widening the study carried on by ISPRA about a "model for the ex-post evaluation of environmental projects effectiveness", based on the integration of DPSIR model (Driving Forces - Pressure - State - Impact - Response) with the EU assessment model for structural funded programmes.

The research directly derives from the need of public administration to test and assess the effectiveness of funded environmental projects and their efficiency, in order to optimize the usage of increasingly scarce resources $[1,2]$. It takes into account the results of a test phase involving broad kinds of projects in various environmental sectors.

The effectiveness point of view introduces a crucial approach to environmental projects evaluation. It leads not only to ex post assessment of their general effects, but deals with a strategic vision, aimed at defining priorities and selecting options. Therefore, even if the model was initially designed to report benefit obtained by already implemented projects, it can also be used to guide public administrations funding towards the most relevant environmental priorities or criticalities in a given area, or towards the most effective option among different projects.

To allow this wider scope, the model offers qualitative and quantitative tools for framing an overall balance of projects environmental effects. It consequently takes into consideration both the ability of the project in order to generate expected positive effects on targeted environmental components (as it deals with environmental projects) and the uneven indirect effects induced on different components.

Within this research, positive expected environmental effect s, directly linked to project objectives are defined results. Uneven, indirect environmental effects, both positive and negative, are considered as impacts. In some cases, these latter may be crucial for a correct evaluation, especially when it is necessary to compare multiple projects having similar purposes.

The model deals with the following evaluation dimensions [3]:

- $\quad$ the degree of consistency/coherence (considering both results and impacts) with the programmatic and environmental context; 
- the effectiveness, i.e. the capacity of the project to achieve its direct objectives and, consequently, to compare with reference values (arising from reference environmental objectives, limitations and thresholds imposed by law, benchmark values) and/or to contribute to improve the state of targeted environmental components;

- $\quad$ the impacts, i.e. the additional effects of the project that do not respond to direct objectives, compared with reference values (programmatic, regulatory, benchmark values, ...). Impacts, both positive and negative, also deal with the ability of the project to affect the context in which it is inserted;

- $\quad$ the cost-effectiveness, i.e. the relation between project resource spending (both economic and environmental) and outcomes (e.g. Euros spent for reducing 1 ton of $\mathrm{CO}_{2}$ emission);

- $\quad$ the efficiency, i.e. economic resources (time and cost) required to implement a functional unit of the project.

The model was built and tested for different projects in the fields of sustainable mobility (car sharing, bike sharing, car-pooling), energy (wind, minihydro, biomass district heating, high efficiency public lighting), waste management (pre-treatment waste platform), and water (sewage plant). The model was also applied to a green public procurement case.

In the diagram of the assessment model (Figure 1), three different modules can be distinguished: the first one (assessment framework) defines common elements (sustainability objectives and environmental context analysis and indicators) which allow comparing projects through evaluating their

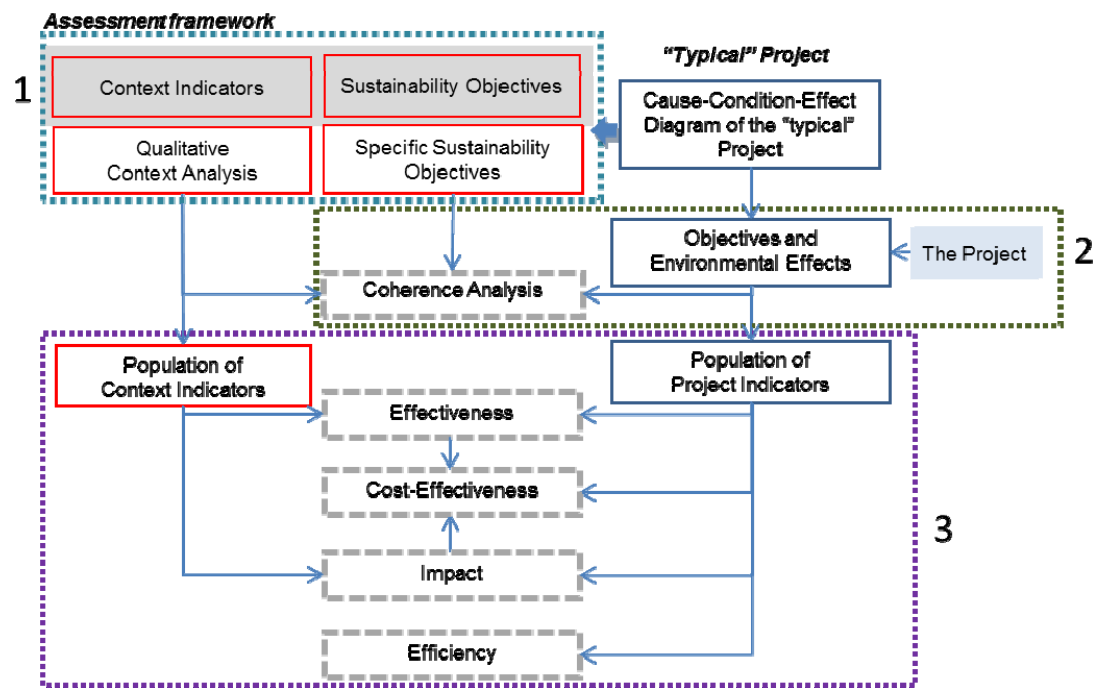

Figure 1: $\quad$ Diagram of the assessment model. 
effectiveness in achieving sustainability objectives; the second one (coherence analysis) foresees an initial qualitative evaluation of project effects with respect to the defined assessment framework, based on a matrix tool; the third module involves the population of indicators for the construction of assessment indices dealing with the evaluation dimensions other than coherence (effectiveness, costeffectiveness, impact and efficiency).

\section{A preliminary module: the assessment framework}

To evaluate one or more real-world projects, the model requires defining specific sustainability objectives obtained by the downscaling of general aims through both the analysis of local programming framework and the analysis of the strengths and weaknesses of the context. The selection of sustainability objectives must also be directly linked to potential effects of projects and therefore depends upon project typologies and peculiarities. In this way, a contextualized framework is associated to each project and allows the comparison among projects dealing with different sectors.

To this aim, the model identifies for each project type (typical project) all potentially significant environmental effects, using a cause-condition-effect graph representation. The graph displays, in a synthetic way, the most important relationships to be evaluated: the results (objectives inherent to the project type), the potential impacts and the context variables affected are therefore represented, in association with indicators that describe them. The graph structure is inspired to the well-known DPSIR model (Driving forces, Pressures, States, Impacts, Responses).

As an example, in Figure 2, the results of the realization of a sewage plant are related to the reduction of pollutants concentration in the wastewater, which may results in improvement of the water quality of the receiving water body (context variable). There are, however, impacts to be considered, such as the consumption of energy and related greenhouse gas emissions, the production of sludge, the impact on the landscape, etc..

Any "condition" necessary to describe the cause-effect relation is shown on the arrows (in Figure 1, for example, on the arrow connecting "wastewater treatment plant" and "landscape", the condition "location in an area of high landscape value" emphasizes that such an effect is particularly significant in sensitive areas).

For each effect identified in the graph, the model extrapolates the relevant objectives from the international and national legislation and programming framework. It also identifies, if any, the related reference values, the regulatory limits with their implementation deadline and any other element that qualify the objectives making them useful for projects evaluation.

For example, for water quality, the sustainability objective requires that by 2015 all significant surface and groundwater water bodies maintain or achieve the "good" status. With reference to the issue of greenhouse gas emissions, the sustainability objective requires that by 2020 emissions are reduced by $20 \%$ compared to 2005, and so on. 


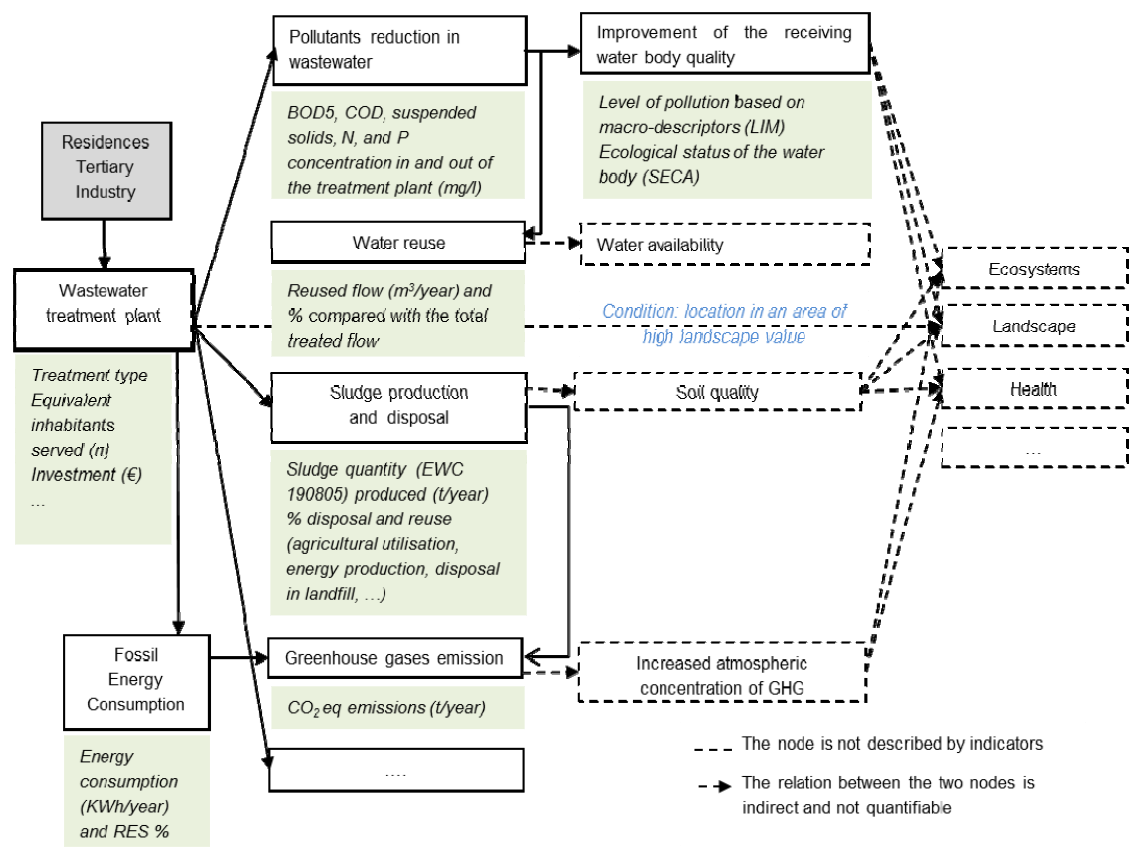

Figure 2: Cause-condition-effect graph for the case of a wastewater treatment plant: the coloured boxes contain the indicators corresponding to the graph nodes; the dashed nodes are not described by indicators.

All the sustainability objectives and the related context indicators are collected in a common general "reference framework" for the evaluation of different project types.

\section{Tackling evaluation dimensions}

The second module deals with the coherence analysis. It verifies the degree of correspondence between the project, the sustainability objectives and the main features of the environmental context to which the project relates to. This quick tool can support the decision-maker in the allocation of funds among alternative projects or project types in a given area.

If done at an early stage of the decision-making process, it allows the public administration to choose, among alternative types of projects, or among similar projects, which one better addresses the most critical issues or the principal strengths of the environmental context.

If done ex-post (when the project has been funded or done), the coherence analysis allows to verify if the project actually addresses the environmental priorities and, if necessary, to redirect any future funding to other types of projects. 


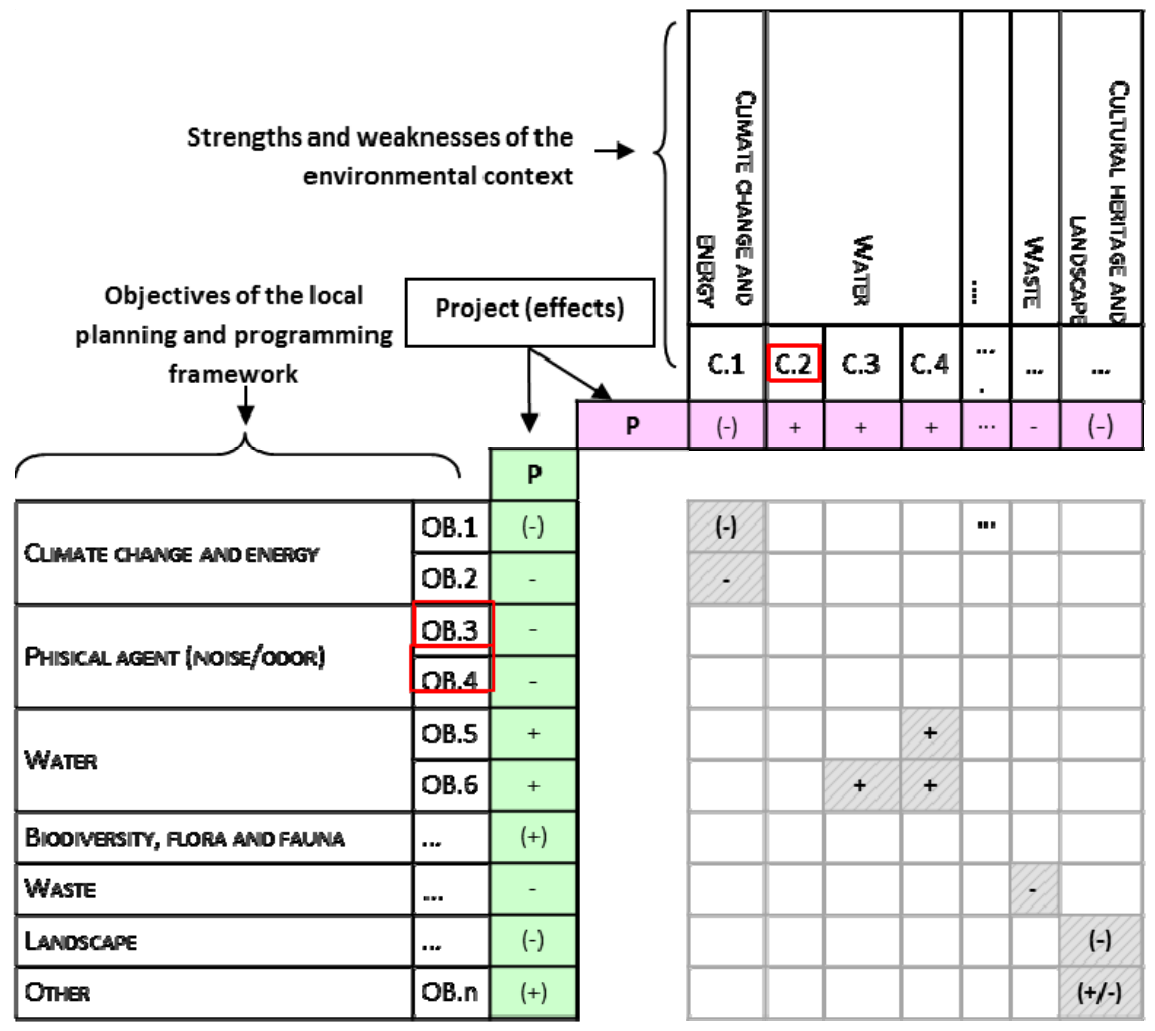

\section{Legend:}

OB.n= objective of the local planning and programming framework not responding to any strength and weakness of the environmental context

C.n = strength or weakness of the local context that is not addressed by any objectives of the planning/programming framework

= objective of the local planning and programming framework responding to one or more strengths and weaknesses of the environmental context, and vice versa
$+=$ positive coherence
$(+)=$ weak or indirect positive coherence
- = negative coherence
$(-)=$ weak or indirect negative coherence
+/- = uncertain positive or negative coherence

Figure 3: $\quad$ Structure of the coherence matrix.

The coherence analysis is carried out through a matrix, by means of which regional and local governments can also verify if the objectives of their own plans and programmes well reflect the environmental peculiarities of the area. Therefore, the coherence matrix, exemplified in Figure 3, highlights the "crossroads" among: the project and the objectives of the local planning and programming framework (green section), the project and the strengths 
/weaknesses of the environmental context (pink section), the strengths/weaknesses of the environmental context and the objectives of the local programs and plans (white section).

The third module aims to quantify performance indicators and assessment indices. Every evaluation dimension is explored through analysing further information and calculating indicators linked to both the project (results and impacts, costs, design parameters) and the context variables potentially intercepted.

In particular, context indicators give back information useful for effectiveness and impact dimensions, as they represent the variation of environmental state at given lapses of time. On the other hand, project indicators (results and impact indicators) provide a range of information useful to all evaluation dimensions.

Each indicator is described by an "information sheet", defining how to detect or populate it, the necessary input data and its use in constructing the assessment indices.

In particular for context, impact or result indicators the information sheet highlights the sustainability objectives described by the indicator and, if existing, any regulatory limits to be respected. Sometimes, some "outcome" indicators could be used as "proxy" of impact or result indicators; for instance, in the case of a car-pooling system, the number of crews per day is a project data (outcome indicator) that can be used as a proxy of results (i.e. reduction of cars and motorcycles on the roads, reduction of traffic emissions, etc.).

The context indicators have to be populated with reference to the appropriate scale, so that it is possible to note changes in their value caused by the project: in general the municipal scale seems the most adapt, although in some cases it may be better to focus on specific areas or territorial elements. In the case of a sewage plant, for example, the water quality to be considered is the one of the receiving water body. The effectiveness assessment analyses the project performance with respect to a reference value, derived from regulations/plans/programs or from a territorial benchmark (projects in the same area) or thematic benchmark (good practice of the same type of project). Moreover, it analyzes if the project is able to improve its environmental context. For instance, a wastewater sewage plant is effective if it is able to improve the water quality of the receiving water body; a district heating plant, if it contributes to the greenhouse gases emissions reduction in the local area.

The effectiveness index represents the project performance, measured by result indicators, with respect of a reference value, allowing the comparison of more projects in "relative" and not "absolute" terms.

As an example, the table 1 shows some result indicators and some effectiveness indices.

The impact assessment takes into account the environmental effects (both positive and negative) not directly related to the achievement of the project objectives.

The relevance of the impacts of a specific project strongly depends on the boundary conditions: only through the indicators can be established, from time to 
time, which impacts are negligible for the specific case and which should be considered in the overall evaluation.

The impact indexes, similarly to the effectiveness ones, represent the project performance with respect to a reference value, allowing the comparison of more projects in "relative" and not "absolute" terms.

For instance, the sludge production is considered an impact of the project type "wastewater sewage plant", but this impact can be considered negligible in these cases: the whole sludge production can be spread, prior treatment, in agriculture; the capability of the sludge treatment plants in the provincial area is over dimensioned compared to the use made of it; the Province, where the sewage plant is located, imports sludge from neighbour Provinces for agronomic uses. If these boundary conditions are verified, the impact "sludge production" enters in the total balance, not in negative rather in positive way.

Table 1: $\quad$ Examples of result indicators and effectiveness indices.

\begin{tabular}{|c|c|c|c|c|c|c|}
\hline $\begin{array}{l}\text { Project } \\
\text { Type }\end{array}$ & \begin{tabular}{|l|} 
Results \\
Indicators
\end{tabular} & Effectiveness Index & \multicolumn{3}{|c|}{ Target Value } & Source \\
\hline \multirow{2}{*}{$\begin{array}{l}\text { Sewage } \\
\text { Plant }\end{array}$} & \multirow{2}{*}{$\begin{array}{l}\text { Average } \\
\text { concentration } \\
\text { input and } \\
\text { output from } \\
\text { the plant } \\
(\mathrm{mg} / \mathrm{l})\end{array}$} & $\begin{array}{l}\text { Average output } \\
\text { concentration/Threshol } \\
\text { d Limit Value (d. lgs } \\
\text { 152/2006, Part } 3 \text { - All. } \\
\text { V) (\%) }\end{array}$ & -- & -- & -- & \\
\hline & & $\begin{array}{l}\text { Decreasing of the input } \\
\text { concentration (\%) }\end{array}$ & $\begin{array}{c}\text { BOD5 } \\
(\mathrm{mg} / \mathrm{lt}) \\
80\end{array}$ & $\begin{array}{c}\mathrm{COD} \\
(\mathrm{mg} / \mathrm{lt}) \\
75\end{array}$ & $\begin{array}{c}\mathrm{SS} \\
(\mathrm{mg} / \mathrm{lt}) \\
90\end{array}$ & $\begin{array}{c}\text { d. lgs } \\
\text { 152/2006, } \\
\text { Part 3- } \\
\text { All. V }\end{array}$ \\
\hline $\begin{array}{l}\text { Car } \\
\text { pooling }\end{array}$ & $\begin{array}{l}\text { Decreasing of } \\
\text { the driven } \\
\text { distance by } \\
\text { car and } \\
\text { motorbike } \\
\text { (car-km, } \\
\text { motorbike- } \\
\text { km) } \\
\end{array}$ & $\begin{array}{l}\text { Decreasing of the } \\
\text { driven distance by car } \\
\text { and motorbike/Total } \\
\text { driven distance by car } \\
\text { and motorbike by the } \\
\text { employees of body that } \\
\text { triggered the system } \\
\text { (\%) }\end{array}$ & \multicolumn{3}{|c|}{$10-15 \%$} & $\begin{array}{l}\text { Bench- } \\
\text { mark } \\
\text { from field } \\
\text { studies }\end{array}$ \\
\hline $\begin{array}{l}\text { District } \\
\text { heating }\end{array}$ & $\begin{array}{l}\text { Avoided } \\
\mathrm{CO}_{2} \mathrm{eq} \\
\text { emissions } \\
\text { (ton/year) }\end{array}$ & $\begin{array}{l}\text { Avoided } \mathrm{CO}_{2} \mathrm{eq} \\
\text { emissions } / \mathrm{CO}_{2} \mathrm{eq} \\
\text { emissions from the } \\
\text { municipal energy uses, } \\
\text { civil sector (\%) }\end{array}$ & \multicolumn{3}{|c|}{$\begin{array}{l}20 \% \text { compared to the } \\
\text { value of } 2005 \text { (for the } \\
\text { whole municipal } \\
\text { territory) }\end{array}$} & $\begin{array}{l}\text { Munici- } \\
\text { pal Plan } \\
\quad \text { for } \\
\text { Sustain- } \\
\text { able } \\
\text { Energy }\end{array}$ \\
\hline
\end{tabular}

As example, some impact indices are in table 2.

The cost-effectiveness assessment determines if the project is able to achieve its results (i.e. to be "effective") with the least possible use of resources, both economic and environmental. The cost-effectiveness indexes are therefore the cost (both economic and environmental) per unit of output, and derive from 
Table 2: $\quad$ Examples of impact indices.

\begin{tabular}{|l|l|}
\hline Project type & Impacts indexes \\
\hline \multirow{2}{*}{$\begin{array}{l}\text { Sewage } \\
\text { plant }\end{array}$} & Sludge sent to landfill/Total sludge (\%) \\
\cline { 2 - 2 } & Sludge sent to landfill/Sludge sent to landfill in the whole Province (\%) \\
\cline { 2 - 2 } & Impact on landscape \\
\hline $\begin{array}{l}\text { District } \\
\text { heating }\end{array}$ & $\begin{array}{l}\text { Generated ash/Non-hazardous special waste generated in the whole } \\
\text { Province (\%) }\end{array}$ \\
\hline
\end{tabular}

*The "impact on landscape" considers the degree of impact of the project compared to the sensitivity of the environment (Lombardy Region, 2002).

the intersection of outcome indicators with indicators of environmental impact and economical cost.

The cost-effectiveness thus allows the comparison of alternative projects, pursuing the same objective or generating homogeneous environmental effects with respect to economic and environmental resources used.

For example, in the case of the sewage plant, in addition to the plant construction and management costs, there are some environmental costs associated with the consumption of non-renewable energy, the production of sludge, the amount of not recovered sludge, compared with results obtained in terms of equivalent inhabitants served, the increase of the load treated in the ATO and the reduction of pollutant concentrations.

As example, some cost-effectiveness indexes are in the table below.

Table 3: $\quad$ Examples of cost-effectiveness indices.

\begin{tabular}{|l|l|}
\hline Project type & Cost-effectiveness indexes \\
\hline \multirow{4}{*}{$\begin{array}{l}\text { Sewage } \\
\text { plant }\end{array}$} & $\begin{array}{l}\text { Total plant construction cost /Pollutant } x \text { concentration decrease (input- } \\
\text { output) [€/mg/lt] }\end{array}$ \\
\cline { 2 - 2 } & Total plant construction cost/Load treated in the ATO increase [€/\%] \\
\cline { 2 - 2 } & $\begin{array}{l}\text { Not renewable energy consumption/E.I. served (plant in operation) } \\
{[\mathrm{kWh} / \text { E.I. served] }}\end{array}$ \\
\hline Car pooling & $\begin{array}{l}\text { Total cost (annual)*/Annual driven distance (from cars and motorbike) } \\
\text { decrease [€/km] }\end{array}$ \\
\hline \multirow{2}{*}{$\begin{array}{l}\text { District } \\
\text { heating }\end{array}$} & $\begin{array}{l}\text { Total cost (annual) } * / \text { Avoided } \mathrm{CO}_{2} \text { eq emissions per year [€/ton } \\
\mathrm{CO}{ }_{2} \text { eq] }\end{array}$ \\
\cline { 2 - 2 } & Generated ash/Energy production $[\mathrm{kg} / \mathrm{MWh}]$ \\
\hline
\end{tabular}

*Includes the investment cost divided by the plant life-time and the management cost per year.

In addition to the environmental evaluations described above, the efficiency assessment evaluates if the project is able to get an outcome unit with the least use of resources (time and cost); it could also be useful to verify if project costs are reliable or to compare different alternatives.

The efficiency indexes thus describe costs and/or timing per functional unit and are built by intersecting some indicators.

As example, some efficiency indexes are in the table below.

If used ex-ante, the assessment model allows estimating the project positive effects on the territory and could be useful to compare and order alternatives (i.e. 
Table 4: $\quad$ Examples of efficiency indices.

\begin{tabular}{|l|l|}
\hline Project Type & Efficiency Indexes \\
\hline Sewage Plant & Total cost (annual)*/E.I. served (plant in operation) [€/E.I.] \\
\hline Car pooling & Total cost (annual)*/Number of crews [€/n] \\
\hline \multirow{2}{*}{ District heating } & Total plant construction cost/District heating network length [€/km] \\
\cline { 2 - 2 } & Total plant construction cost/Increase of Heated volume $\left[€ / \mathrm{m}^{3}\right]$ \\
\hline
\end{tabular}

* Includes the investment cost divided by the plant life-time and the management cost per year.

for a call of proposals). Ex-post, once the project has been implemented, the model allows verifying the achievement of the declared objectives and monitoring the real benefits and impacts. Even in this case, it is useful to have carried on an ex-ante assessment, in order to compare the project's declared objectives with the achieved ones.

The model has been fully developed for the types of projects mentioned in the introduction, for which has been tested on case studies inspired by real cases. In case of unavailability or partial availability of data relating to the real cases, they have been substituted by realistic ones, inspired to similar real cases or to examples taken from literature.

\section{Conclusion}

The developed model is useful to compare alternative projects to be localized in the same area or in different areas. At this purpose, it is necessary to use one or more composite performance indices. For the comparison, indicators and indices, described by different measure units, have to be normalized and combined to define a synthetic performance index. To this aim, the model proposes the use of "classical” multi-criteria analysis by Keene and Raiffa [4].

The developed model can support the decision-making process in its different steps.

Assessment process efficiency is strictly linked to its ability in driving the decision making process by intercepting it in its preliminary phases. Therefore, the model can help since the beginning the decision-maker, i.e. a public administration, in choosing which type of project has to be financed. It can also provide a range of appropriate locations for its implementation, minimizing environmental negative impacts. In this step, the "coherence analysis" is the most effective instrument that allows comparing the envisaged types of projects on the basis of strengths and weaknesses of the territory and programmatic priorities therein. Where available, it must link to coherence analysis provided by reference plans (at territorial or sectorial level) or by their strategic environmental assessments.

Once assessed which type of projects will be financed and how to finance them, the model can also support public administrations in drafting calls for tenders or proposals by providing a set of selection criteria coherent with defined performance indicators and indices. It has to take into proper account both project potential benefits and impacts on the environment as well as to cover all 
the mentioned evaluation dimension. Applicants will be asked to produce proper information in order to carry out assessment activity and to select beneficiaries.

When selected, beneficiaries will be requested to provide data and information to verify project performances through calculating indicators during its implementation. Ex ante values will be verified and compared with an ex-post assessment, also through questionnaires and/or direct analysis. Furthermore, if the applicants or beneficiaries are public bodies or agencies, they are expected to provide specific information and data about environmental context and their territorial plans and programs, in order to make the evaluation possible.

In spite the research put in evidence many useful potential application for Public Administration, there are still some issues open, that need to be further deepened in order to develop an easy to use but effective tool that can really back up the decision making process.

One issue related to the actual application of the proposed model is the definition of appropriate targets for indicators and indices, which is problematic particularly when they have to be based not on regulatory targets or policy goals. At this purpose, it seems fundamental to build a sustainability strategy articulated at various scales, as challenged by European strategies and documents and envisaged by an Italian piece of legislation which is still not implemented (legislative decree n.152/2006 and subsequent amendments). It would represent the reference for a meaningful and shared targets definition both at local and large scales, framing at the same time planning and assessment activities.

\section{References}

[1] Sathaye, J., Norgaard, R. and Makundi, W., A Conceptual Framework for the Evaluation of Cost-Effectiveness of Projects to Reduce Ghg Emissions and Sequester Carbon. Lawrence Berkeley Laboratory Report, LBL-33589, Berkeley, CA, 1993.

[2] Connor, J., Ward, J., and Bryan, B., Exploring the Cost Effectiveness of Land Conservation Auctions and Payment Policies. The Australian Journal of Agricultural and Resource Economics, 52(3), pp. 303-319, 2008.

[3] Funtowicz, S.O., Martinez-Alie, J., Munda, G., and Ravetz, J.R., Information tools for environmental policy under conditions of complexity. European Environment Agency Environmental Report Issue No 9, Luxembourg, 1999. Online http://www.eea.europa.eu/publications/ ISSUE09.

[4] Keene, R.L., Raiffa H. Decisions with Multiple Objectives. John Wiley and Sons, New York, 1976. 